\title{
Crescimento de plantas de tectona grandis sob restrição hídrica
}

\author{
Tectona grandis plant growth under water restrictions
}

\author{
Fábio Santos Matos ${ }^{1}$, Igor Alberto Silvestre Freitas ${ }^{2}$, Brenda Rodrigues de Souza ${ }^{2}$, Vinícius de Araújo \\ Lopes $^{2}$, Vanessa do Rosário Rosa ${ }^{2}$ \\ ${ }^{1}$ Professor orientador da Universidade Estadual de Goiás (UEG), Câmpus Ipameri, rodovia GO 330, km 241, \\ anel viário, Ipameri, Goiás, e-mail: fabio.agronomia@hotmail.com \\ ${ }^{2}$ Estudantes de graduação da UEG, Câmpus Ipameri, Goiás
}

Recebido em: 07/06/2016

\begin{abstract}
Resumo: O presente estudo teve como objetivo identificar a estratégia de sobrevivência de plantas de Tectona grandis sob déficit hídrico para posterior utilização como critério de pré-seleção em programas de melhoramento genético. O trabalho foi conduzido em casa de vegetação coberta com plástico transparente e laterais fechadas com sombrite $50 \%$. As sementes de Tectona grandis foram semeadas em vasos de 12 litros contendo uma mistura de solo, areia e esterco na proporção de 3:1:0,5 respectivamente. Utilizou-se o delineamento experimental inteiramente casualizado com cinco tratamentos e seis repetições. A partir do $101^{\circ}$ dia após a germinação, as plantas foram submetidas a regimes hídricos diferenciados: plantas diariamente irrigadas com volume fixo de água correspondente a $0 \%, 25 \%, 50 \%, 75 \%$ e $100 \%$ da evapotranspiração diária durante 20 dias e, em seguida, submetidas as análises: Teor relativo de água, carotenoides totais, razões de massa foliar, caulinar e radicular, biomassa total, altura da planta, diâmetro do caule e transpiração. Em condição de déficit hídrico as plantas de Tectona grandis mantêm-se vivas com reduzido crescimento vegetativo, para tal, as plantas reduzem a área foliar e apresentam como estratégia de sobrevivência um eficiente mecanismo de fechamento estomático em função da elevada sensibilidade dos estômatos. O controle estomático da transpiração pode ser utilizado para pré-seleção de materiais promissores para programas de melhoramento genético.
\end{abstract}

Palavras chave: Teca, seca, silvicultura

\begin{abstract}
This study aimed to identify strategy survival of plant Tectona grandis under drought for later use as a pre-selection criterion in breeding programs. The work was carried out in a greenhouse covered with clear plastic sides and closed with 50\% shade. The Tectona grandis seeds were sown in 12-liter vessels containing a mixture of soil, sand and manure in the proportion of 3:1:0.5 respectively. We used a completely randomized design with five treatments and six repetitions. As of 101 days after germination, the plants were subjected to differential water systems: daily irrigated plants with corresponding water fixed volume to $0 \%, 25 \%, 50 \%, 75 \%$ and $100 \%$ of the daily evapotranspiration for 20 days, and then subjected to analysis: Relative water content, total carotenoids, foliar, root and root mass, total biomass, plant height, stem diameter and transpiration. In water stress conditions the plant Tectona grandis remain alive with reduced vegetative growth, for such plants reduce leaf area and feature as a survival strategy an efficient stomatal closure mechanism due to the high sensitivity of stomata. The stomatal control of transpiration can be used for pre-selection of promising materials for breeding programs.
\end{abstract}

Keywords: Teak, dry, forestry

\section{Introdução}

O Brasil apresenta grande potencial para exploração de florestas plantadas em grande parte de sua extensão territorial em função de suas características edafoclimáticas, biodiversidade e disponibilidade de área, bem como comprovada competência técnica no campo da ciência florestal e agrícola. A competitividade do setor florestal 


\section{Revista Agrarian}

ISSN: 1984-2538

brasileiro, fruto das condições climáticas e da tecnologia desenvolvida pelas empresas e instituições de pesquisa faz com que o país ocupe posição de destaque no cenário mundial (Ferreira et al., 2012; Souza et al., 2015). O setor florestal responde por $3,5 \%$ do Produto Interno Bruto (PIB) e gera 4,7 milhões de empregos diretos e indiretos (Abraf, 2016). A exploração de florestas plantadas atenua o desmatamento e contribui para a preservação de nascentes e biodiversidade natural. Estima-se que de 0,7 a $1 \%$ do território brasileiro seja ocupado com florestas plantadas e $56,1 \%$ com florestas naturais (Da Silva et al., 2013).

Apesar do elevado potencial brasileiro no setor florestal, o país pode produzir mais e transferir riqueza para outros segmentos da economia. A crescente demanda mundial por produtos madeireiros tem proporcionado a abertura de novos mercados e a busca de novas fontes produtoras, ampliando o horizonte para o setor florestal. Neste contexto, a Tectona grandis apresenta-se como alternativa para o suprimento sustentável da indústria de base florestal no Brasil (Drescher, 2004).

A Tectona grandis é originária da Ásia e encontra-se em expansão nas regiões CentroOeste e Norte do Brasil. O principal produto dessa espécie é a madeira de alta qualidade. $\mathrm{O}$ valor de mercado para a madeira de Tectona grandis madura, livre de nós e com diâmetro para serraria, chega a superar o valor comercial do mogno brasileiro, cujo metro cúbico cerrado chega a custar US\$ 3.000,00 (Da Silva et al., 2013; Sá et al., 2010). Em todo o mundo, a Tectona grandis é valorizada pela qualidade da madeira, bem como pela rusticidade, sendo utilizada principalmente na indústria naval, móveis, estruturas, pisos, peças torneadas, chapas, painéis, postes e dormentes, trata-se de umas das espécies mais procuradas e valorizadas no mercado de madeiras pela durabilidade e qualidade estética (Tonini et al., 2009). No Brasil os plantios de teca tem crescido progressivamente, somente entre 2007 e 2013 as área de plantios comerciais aumentou em $36 \%$ e a região Centro-Oeste passou a produzir cerca de 0,7 milhão de $\mathrm{m}^{3} /$ ano de teca com produtividade média anual variando de 15 a $20 \mathrm{~m}^{3} \mathrm{ha}^{-1}$ (Anuário estatístico da Abraf, 2016). Estima-se que os plantios de teca atendam apenas $1 \%$ da demanda mundial de madeiras nobres (Schuhli \& Paludzyszyn, 2010) e, dessa forma, torna necessário a maior exploração desta espécie tão valorizada pelo mercado mundial de madeira.

As informações a respeito do crescimento da Tectona grandis em condições de estresses abióticos são escassas e insuficientes para o desenvolvimento de plantios em condições marginais. A disponibilidade de conhecimento do desempenho fisiológico da Tectona grandis sob salinidade, deficiência nutricional e déficit hídrico é necessário para exploração comercial da espécie em regiões áridas e semiáridas. À medida que os recursos hídricos tornam-se escassos, o desenvolvimento de plantas tolerantes a seca passa a ser prioridade para obtenção de altas produtividades. A seleção de plantas com eficientes estratégias de tolerância ao déficit hídrico constitui importante ferramenta para o melhoramento genético de plantas. A escolha de espécies tolerantes ao déficit hídrico assegura renda aos produtores rurais de ambientes semiáridos.

A tolerância a seca é uma resultante de várias características morfológicas, fisiológicas e moleculares (área foliar, movimento estomático, expressão de genes e outras) que se expressam diferente e concomitantemente, dependendo da severidade e da taxa de imposição do déficit hídrico, da idade e das condições nutricionais da planta, do tipo e da profundidade do solo, da carga pendente de frutos, da demanda evaporativa da atmosfera e da face de exposição do terreno. Portanto, a adoção de uma única estratégia de adaptação a seca é, certamente, inadequada para qualquer tipo de ambiente (Sambatti \& Caylor, 2007; Taiz \& Zeiger, 2013; Matos et al., 2014).

Tendo em vista a necessidade de buscar informações sobre o desempenho fisiológico da Tectona grandis, bem como o melhor entendimento das alterações morfofisiológicas para tolerar a seca, possibilitando sua exploração comercial em condições de baixa disponibilidade hídrica, o presente estudo teve como objetivo identificar a estratégia de sobrevivência de plantas de Tectona grandis sob déficit hídrico para fomentar programas de melhoramento genético.

\section{Material e métodos}

O trabalho foi conduzido em casa de vegetação coberta com plástico transparente e 


\section{Revista Agrarian}

ISSN: 1984-2538

laterais fechadas com sombrite $50 \%$ na Universidade Estadual de Goiás, Campus de Ipameri (Lat. $17^{\circ} 43^{\prime} 19^{\prime}$ ' $\mathrm{S}$, Long. $48^{0} 09^{\prime} 35^{\prime \prime} \mathrm{W}$, Alt. $773 \mathrm{~m}$ ), Ipameri, Goiás. Esta região possui clima tropical com inverno seco e verão úmido (Aw), de acordo com a classificação de Köppen. $\mathrm{O}$ delineamento experimental utilizado foi $\mathrm{o}$ inteiramente casualizado com cinco tratamentos e seis repetições. Sementes de Tectona grandis oriundas de uma única planta matriz foram coletadas e semeadas em vasos de 12 litros contendo uma mistura de latossolo vermelho amarelo, areia e esterco na proporção de 3:1:0,5 respectivamente. A análise química da mistura revelou os valores demonstrados na Tabela 1.

Tabela 1. Características químicas do substrato utilizado no experimento. UEG-Ipameri/GO.

\begin{tabular}{|c|c|c|c|c|c|c|c|c|c|c|}
\hline \multirow{2}{*}{ Profundidade } & \multirow{2}{*}{$\begin{array}{c}\mathrm{pH} \\
\mathrm{em} \\
\mathrm{CaCl}_{2} \\
\end{array}$} & \multirow{2}{*}{$\begin{array}{l}\text { M.O. } \\
\left(\text { g.dm }{ }^{-3}\right)\end{array}$} & \multirow{2}{*}{ 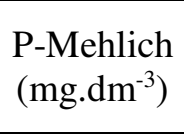 } & \multicolumn{6}{|c|}{ Complexo Sortivo $\left(\mathrm{cmol}^{\left.-\mathrm{dm}^{-3}\right)}\right.$} & \multirow[b]{2}{*}{$\mathrm{V} \%$} \\
\hline & & & & $\mathrm{K}$ & $\mathrm{Ca}$ & $\mathrm{Mg}$ & $\mathrm{Zn}$ & $\mathrm{H}+\mathrm{Al}$ & CTC & \\
\hline 0 a 20 & 6,4 & 19 & 2,4 & 109 & 3,2 & 1,6 & 27,7 & 1,5 & 6,58 & 77,2 \\
\hline
\end{tabular}

Após análise da composição da mistura foi decidido não realizar adubação nem corrigir o $\mathrm{pH}$ do substrato. As mudas foram irrigadas diariamente com volume variável de água correspondente a $100 \%$ da evapotranspiração diária até os 100 dias de idade. Como o coeficiente da cultura $(\mathrm{kc})$ para Tectona grandis ainda não foi determinado, utilizamos o kc igual a 1,00 seguindo estimativa da FAO 56 (Allen et al., 1998) para um grupo de culturas em estádio de crescimento inicial.

O volume de água fornecido foi fixo durante imposição dos tratamentos e estimado determinando a evapotranspiração de referência e o coeficiente da cultura. Para determinar a evapotranspiração da cultura, utilizou-se a equação: $\mathrm{ETc}=$ ETo $\mathrm{x}$ kc; Onde: $\mathrm{ETc}=$ evapotranspiração da cultura; $\mathrm{kc}=$ coeficiente da cultura; ETo = Evapotranspiração de referência

O cálculo da ETo diária foi feito pelo método de Penman-Monteith recomendado pela FAO (Smith et al., 1991) utilizando os dados diários de temperatura máxima e mínima do ar, umidade relativa do ar, insolação e velocidade do vento obtidos na Estação Meteorológica do INMET localizado no município de Ipameri, GO.

Aos 101 dias após a germinação quando as mudas estavam uniformes em altura, diâmetro e número de folhas, as plantas foram submetidas a regimes hídricos diferenciais: plantas diariamente irrigadas com volume de água correspondente a $0 \%, \quad 25 \%, \quad 50 \%, \quad 75 \% \quad$ e $\quad 100 \%$ da evapotranspiração diária durante 20 dias e, em seguida, submetidas às seguintes analises: Teor relativo de água, carotenoides totais, razões de massa foliar, caulinar e radicular, biomassa total, altura da planta, diâmetro do caule e transpiração.

O número de folhas foi mensurado por contagem, o comprimento e largura das folhas, altura de planta e diâmetro do caule foram mensurados utilizando régua graduada $\mathrm{e}$ paquímetro digital. As análises destrutivas foram realizadas em seguida, quando folhas, raízes e caules foram destacados e colocados para secar em estufa a $72{ }^{\circ} \mathrm{C}$ até atingir massa seca constante e, em seguida, pesados separadamente. Com os dados de massa seca foram calculados a biomassa total somando a massa seca da raiz, caule e folhas, razão de massa da folha (RMF), razão de massa da raiz (RMR) e razão de massa do caule (RMC) dividindo o valor da massa seca de cada órgão pela biomassa total.

A transpiração diária total da planta foi mensurada pela diferença de peso dos vasos. Inicialmente cada vaso foi inserido dentro de um saco plástico fixado com borracha no caule da planta, ficando apenas a parte aérea (folhas e caule) externa ao saco, em seguida, o conjunto vaso com planta e saco plástico foram pesados às 18:00 h (massa 01) e 24 horas depois novamente pesados (massa 02). A transpiração total foi estimada pela diferença entre a massa 01 e massa 02.

Para a determinação da concentração de carotenoides totais foram retirados discos foliares (terceiro par de folhas totalmente expandidas) de área conhecida e colocados em vidros contendo dimetilsulfóxido (DMSO). Posteriormente, foi 


\section{Revista Agrarian}

ISSN: 1984-2538

feita extração em banho-maria à $65^{\circ} \mathrm{C}$ por três horas. Alíquotas foram retiradas para leitura espectrofotométrica a $480 \mathrm{~nm}$ e a concentração de carotenoides foi determinada seguindo as equações propostas por Wellburn (1994).

$\mathrm{C}_{\mathrm{a}}-12,47 \mathrm{~A}_{665,1}-3,62 \mathrm{~A}_{649,1}$

$\mathrm{C}_{\mathrm{b}}=25,06 \mathrm{~A}_{649,1}-6.5 \mathrm{~A}_{665,1}$

Carotenoides $=\left(1000 \mathrm{~A}_{480}-1.29 \mathrm{C}_{\mathrm{a}}-53,78 \mathrm{C}_{\mathrm{b}}\right) / 220$

Onde:

$\mathrm{C}_{\mathrm{a}}=$ Clorofila $_{\mathrm{a}}, \mathrm{C}_{\mathrm{b}}=$ Clorofila $\mathrm{b}, \mathrm{A}_{665,1}=$ Absorvância a 665,1 nm (nanômetros)

$\mathrm{A}_{649,1}=$ Absorvância a $665,1 \mathrm{~nm}, \mathrm{~A}_{480}=$

Absorvância a 665,1 nm

Cada regime hídrico correspondeu a um tratamento. As variáveis foram submetidas à análise de variância seguindo delineamento inteiramente casualizado, com cinco tratamentos e seis repetições. Diferenças entre as médias dos tratamentos foram analisadas pelo teste $\mathrm{F}$ a $5 \%$ de probabilidade. Adicionalmente, procedeu-se a análise de regressão, cujo Coeficiente de
Determinação $\left(\mathrm{R}^{2}\right)$ foi obtido pela divisão da soma de quadrados da regressão pela soma de quadrados totais. Todas as análises estatísticas foram realizadas utilizando o software $\mathrm{R}$ ( $\mathrm{R}$ core team, 2017).

\section{Resultados}

O resumo da análise de variância para altura de planta, diâmetro do caule, número de folhas, largura, comprimento das folhas e concentração foliar de carotenoides encontra-se na Tabela 2. O coeficiente de variação foi sempre igual ou inferior a $30 \%$ para todas as variáveis, demonstrando elevada confiabilidade dos dados. A altura da planta, número de folhas e comprimento da folha apresentaram significativa diferença estatística pelo teste $\mathrm{F}$ indicando que existe variação significativa entre os tratamentos para cada uma das variáveis citadas.

Tabela 2. A análise de variância da altura de planta, diâmetro do caule, número de folhas, largura e comprimento das folhas e concentração foliar de carotenoides totais (Car) de mudas de Tectona grandis irrigadas com volume de água referente a 100\% 75\% 50\% 25\% e $0 \%$ da evapotranspiração.

\begin{tabular}{lccccccc}
\hline \multicolumn{1}{c}{$\begin{array}{c}\text { Fonte de } \\
\text { variação }\end{array}$} & \multirow{2}{*}{ GL } & \multicolumn{7}{c}{ Quadrados médios } \\
\cline { 3 - 8 } & & Altura & Diâmetro & $\mathrm{N}^{\mathbf{o}}$ folha & Largura & Comprimento & Car \\
\hline Tratamentos & 4 & $35,2^{*}$ & $22,9^{*}$ & $78,8^{*}$ & $0,98^{\text {ns }}$ & $12,6^{*}$ & $0,26^{\text {ns }}$ \\
Erro & 25 & 8,2 & 2,5 & 7,8 & 2,89 & 9,1 & 0,89 \\
CV (\%) & & 15,6 & 15,9 & 26,0 & 29,0 & 29,2 & 30,0 \\
\hline
\end{tabular}

* significativo a $5 \%$ de probabilidade; $\mathrm{ns}=$ não significativo pelo teste $\mathrm{F}$.

A análise de variância para razões de massa radicular, caulinar e foliar, biomassa total, teor relativo de água e transpiração encontra-se na tabela 3. O coeficiente de variação foi sempre inferior a $30 \%$ para todas as variáveis, demonstrando elevada confiabilidade dos dados conforme relata Gomes \& Garcia, (2002).

Tabela 3. A análise de variância das razões de massa radicular (RMR), caulinar (RMC), foliar (RMF), concentração foliar de biomassa (Biom), teor relativo de água (TRA) e transpiração (Transp.) de mudas de Tectona grandis irrigadas com volume de água referente a $100 \% 75 \% 50 \% 25 \%$ e $0 \%$ da evapotranspiração.

\begin{tabular}{lccccccc}
\hline \multirow{2}{*}{$\begin{array}{c}\text { Fonte de } \\
\text { variação }\end{array}$} & GL & \multicolumn{7}{c}{ Quadrados médios } \\
\cline { 3 - 8 } & & RMR & RMC & RMF & Biom. & TRA & Transp. \\
\hline Tratamentos & 4 & $0,004^{\text {ns }}$ & $0,0001^{\text {ns }}$ & $0,006^{\text {ns }}$ & $15,6^{*}$ & $1784^{*}$ & $6691^{*}$ \\
Erro & 25 & 0,004 & 0,001 & 0,001 & 2,8 & 188 & 162 \\
CV (\%) & & 10,0 & 29,3 & 21,0 & 11,7 & 22,0 & 22,3 \\
\hline
\end{tabular}

* significativo a $5 \%$ de probabilidade; $\mathrm{ns}=$ não significativo pelo teste $\mathrm{F}$. 


\section{(ㅇ. \\ Revista Agrarian \\ ISSN: 1984-2538}

As variáveis altura da planta, número de folhas e comprimento da folha apresentaram crescimento linear e diretamente proporcional à disponibilidade de água (Figura 1). As variáveis largura da folha e concentração foliar de carotenoides não apresentaram diferença estatística significativa pelo teste $\mathrm{F}$ e não se ajustaram a nenhum modelo de regressão
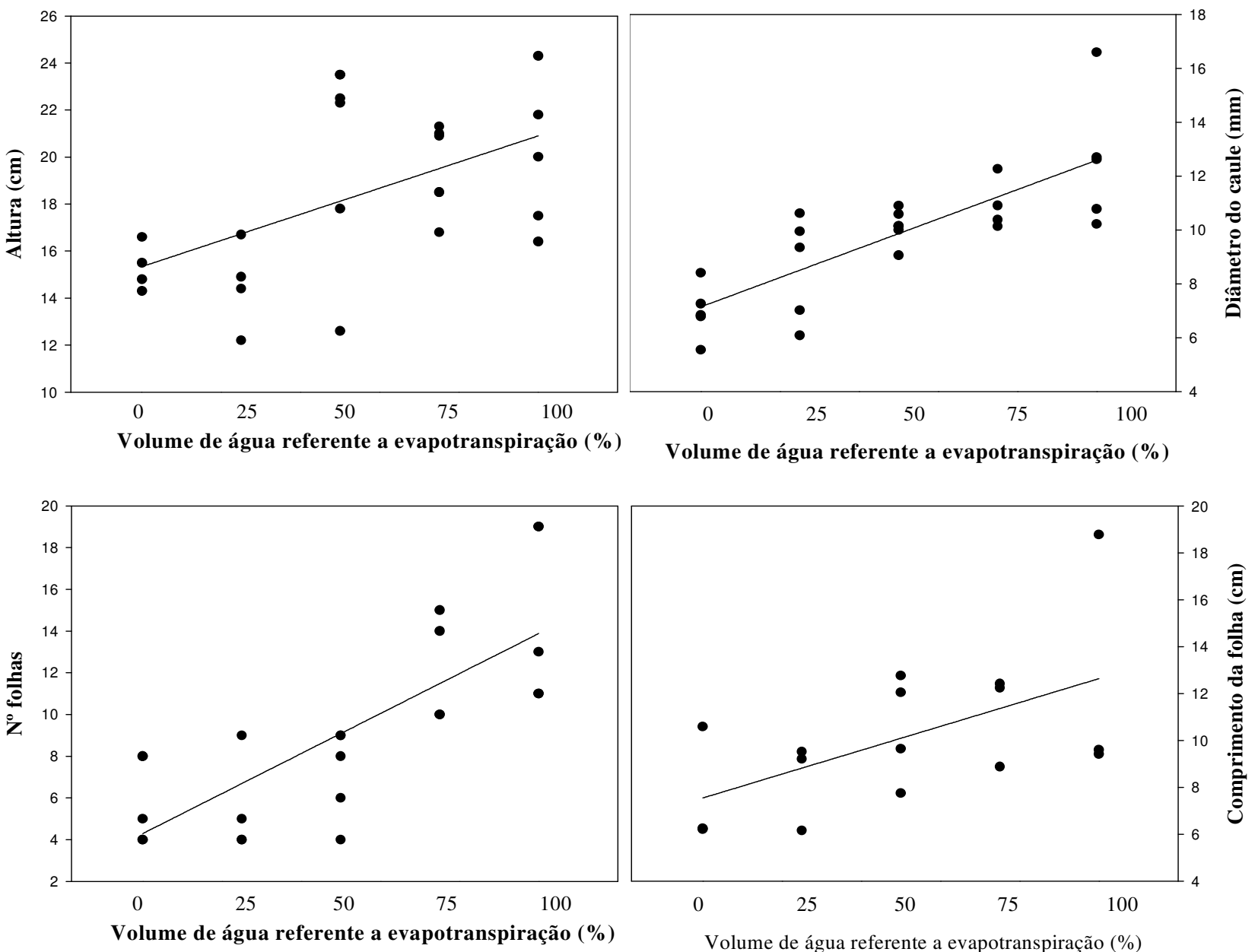

Figura 01. Equações de regressão da altura de planta $\left(Y=15,34+0,056 x, R^{2}=0,71 * *, p=0,006\right)$, diâmetro do caule $\left(\mathrm{Y}=7,14+0,054 \mathrm{x}, \mathrm{R}^{2}=0,80^{* *}, \mathrm{p}<0,0001\right)$, número de folhas $(\mathrm{Y}=4,29+$ $\left.0,096 \mathrm{x}, \mathrm{R}^{2}=0,77^{* *}, \mathrm{p}<0,0001\right)$ e comprimento de folha $\left(\mathrm{Y}=7,55+0,051 \mathrm{x}, \mathrm{R}^{2}=0,68^{*}, \mathrm{p}=\right.$ 0,022 ) de mudas de Tectona grandis irrigadas com volume de água referente a $100 \% 75 \% 50 \%$ $25 \%$ e $\quad 0 \%$ da evapotranspiração. Significativo a $5 \%$ e $* * \quad 1 \%$ de probabilidade.

As variáveis razões de massa radicular, caulinar e foliar e concentração foliar de carotenoides totais não apresentaram variação estatística significativa relacionadas com a variação da disponibilidade de água pelo teste $\mathrm{F}$ e não se ajustaram a nenhum modelo de regressão.
A biomassa total, teor relativo de água e transpiração total da planta apresentaram significativa diferença estatística pelo teste $\mathrm{F}$. Estas variáveis apresentaram crescimento linear e diretamente proporcional à disponibilidade de água (Figura 2). 


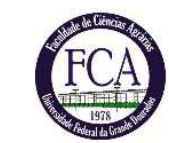

\section{Revista Agrarian}

ISSN: 1984-2538
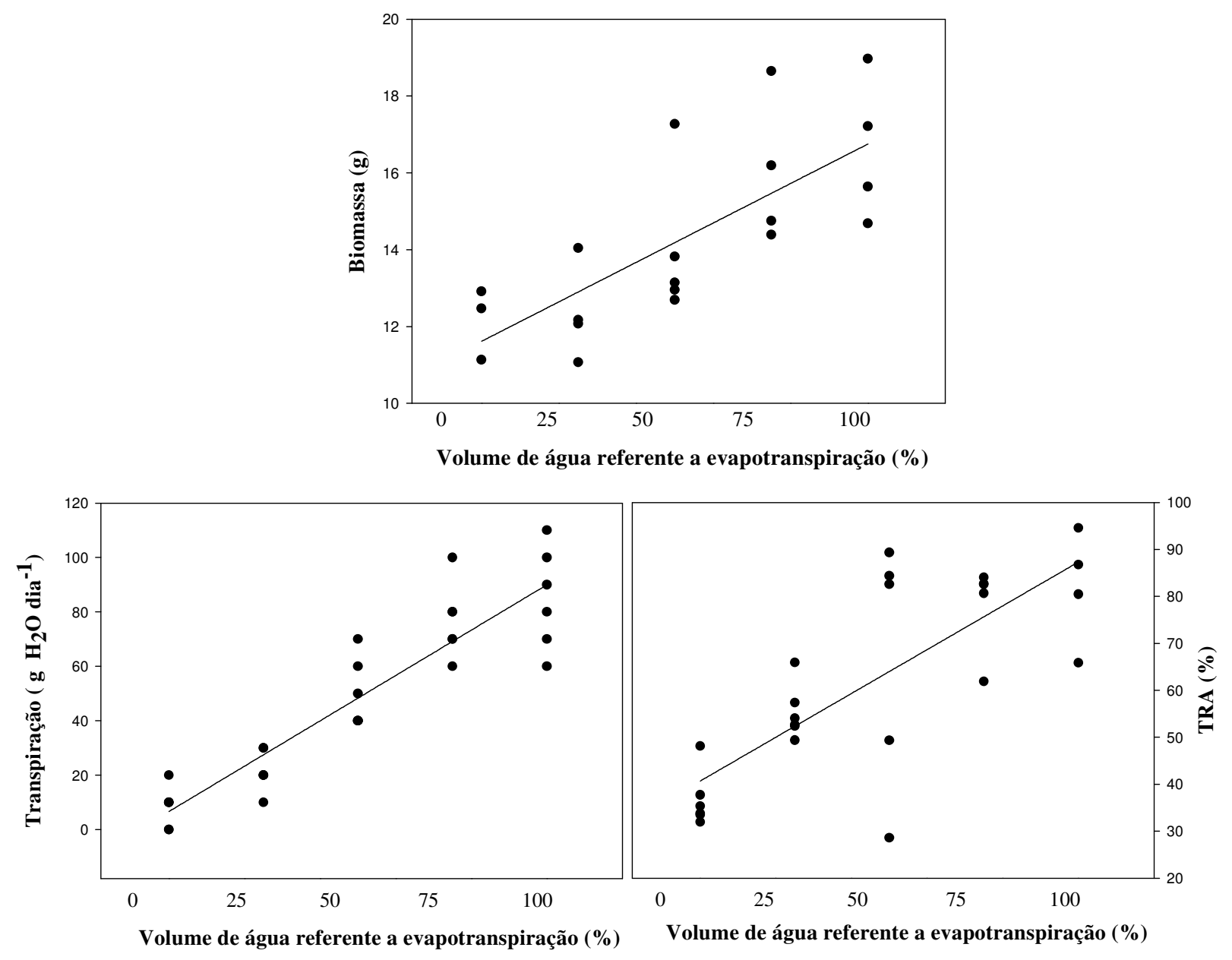

Figura 02. Equações de regressão da biomassa $\left(Y=11,61+0,051 x, R^{2}=0,75^{* *}, p=0,001\right)$, transpiração total $\left(\mathrm{Y}=6,67+0,83 \mathrm{x}, \mathrm{R}^{2}=0,91^{* *}, \mathrm{p}<0,0001\right)$ e teor relativo de água $(\mathrm{Y}=40,69+$ $\left.0,47 \mathrm{x}, \mathrm{R}^{2}=0,78^{* *}, \mathrm{p}<0,001\right)$ de mudas de Tectona grandis irrigadas com volume de água referente a $100 \% 75 \% 50 \%$ 25\% e $0 \%$ da evapotranspiração. Significativo a 5\% e ** 1\% de probabilidade.

\section{Discussão}

Em condições naturais, os estresses abióticos podem causar danos irreversíveis às plantas. A tolerância ao déficit hídrico pode representar expansão da fronteira agrícola pela obtenção de retorno econômico em áreas inaptas. Possivelmente a elevada adaptabilidade às variações de clima e solo aliada a rusticidade das plantas de Tectona grandis (Floréz, 2012) tenham contribuído para a planta tolerar o déficit hídrico.

$$
\text { A restrição hídrica interferiu }
$$
profundamente nas variáveis de crescimento de plantas de Tectona grandis. A iniciação e desenvolvimento do primórdio foliar são dependentes do status hídrico da planta. $\mathrm{O}$ déficit hídrico resultou em menor disponibilidade de água para expansão celular e metabolismo vegetal. Dessa forma, às variáveis determinantes para o crescimento vegetal (altura, diâmetro do caule, $\mathrm{n}^{\mathrm{o}}$ de folhas e tamanho da folha) que dependem de turgidez para expansão celular foram significativamente afetadas. Segundo Taiz \& Zeiger, (2013), de toda a água absorvida pela planta, $97 \%$ é transpirada, 2\% utilizada na expansão celular e $1 \%$ no metabolismo vegetal. A redução do número e tamanho das folhas são importantes estratégias de tolerância ao déficit hídrico por reduzir a superfície transpirante. Dentre as mudanças morfológicas em condição de déficit hídrico, o reduzido número e tamanho das folhas são as mais expressivas e indispensáveis para retardar a desidratação (Santana et al., 2011). 


\section{Revista Agrarian}

ISSN: 1984-2538

O ajustamento da área foliar total e número de folhas são necessários para suportar o estresse imposto e aclimatar-se a nova condição (Matos et al., 2014). O déficit hídrico estimula novas capacidades metabólicas e/ou estruturais mediadas pela alteração da expressão gênica (Sharp al., 2004). A deficiência hídrica provoca alterações morfológicas e anatômicas nas plantas a ponto de desbalancear a absorção de água e a taxa transpiratória.

A acentuada redução da taxa transpiratória e teor relativo de água indicam que a espécie possui elevada sensibilidade estomática e que a hidratação dos tecidos é altamente vulnerável à disponibilidade de água no solo. Segundo Souza et al. (2015) a redução do número de folhas, pequena variação do teor relativo de água com manutenção da hidratação das folhas e redução da transpiração em plantas de Eucalyptus urophylla sob baixa disponibilidade de água é indício de tolerância ao déficit hídrico. No presente trabalho o teor relativo de água decresceu acetuadamente e as folhas não permaneceram hidratadas em plantas sob déficit hídrico.

A redução da biomassa total é evento comum em plantas sob déficit hídrico (Matos et al., 2014). O menor número e tamanho das folhas, associadas a reduzida condutância estomática afetaram a taxa de assimilação líquida de carbono em plantas submetidas ao déficit hídrico, resultando em menor taxa cumulativa de carbono em nível de dossel e, consequentemente, menor acúmulo de biomassa. As plantas de Tectona grandis mostraram-se sensíveis ao déficit hídrico. Segundo Schuhli e Paludzyszyn, (2010) a teca desenvolve bem em solos profundos e úmidos com precipitação anual mínima em torno de 1200 $\mathrm{mm}$ e estação seca curta ou inexistente.

\section{Conclusões}

Em condição de déficit hídrico as plantas de Tectona grandis mantêm-se vivas com reduzido crescimento vegetativo em relação às plantas irrigadas com volume de água correspondente a $100 \%$ da evapotranspiração, para tal, as plantas ajustam a área foliar e apresentam como estratégia de sobrevivência, um eficiente mecanismo de fechamento estomático em função da elevada sensibilidade dos estômatos.
O controle estomático da transpiração pode ser utilizado para pré-seleção de materiais promissores para programas de melhoramento genético.

\section{Agradecimentos}

À Universidade Estadual de Goiás (UEG), Coordenação de Aperfeiçoamento de Pessoal de nível superior (CAPES) e Fundação de Amparo à Pesquisa do Estado de Goiás (FAPEG) pelo financiamento do projeto: AUXPE 2370/2014.

\section{Referência}

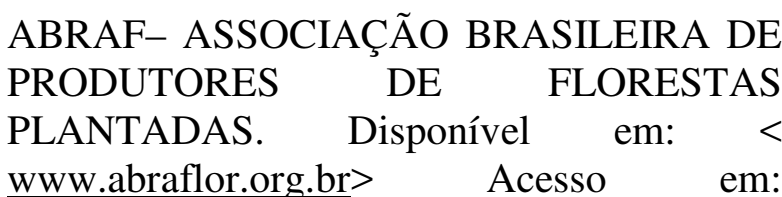
30/06/2016.

ALLEN, R.G.; PEREIRA, L.S.; RAES, D.; SMITH, M. Crop evapotranspiration: guidelines for computing crop water requirements. Rome: FAO, 300p. (FAO. Irrigation and Dranaige Paper, 56), 1998.

DA SILVA, C.V.M.; YAMAKI, K.Y.; SILVA, A.G. Identificação e caracterização da entomofauna em plantios de teca (Tectona grandis). Nucleus, v.10, n.2, 2013.

DRESCHER, R. Crescimento e produção de Tectona grandis Linn. F., em povoamentos jovens de duas regiões do Estado de Mato Grosso. 2004., 133p. Tese (Doutorado em Engenharia Florestal) - Universidade Federal de Santa Maria, Santa Maria, 2004.

FERREIRA, S.M.; PETRAUSKI, C.; GLÁUCIO MARCELINO MARQUES, G. M.; SILVA, M. L.; CORDEIRO, S. A.; SOARES, N. S. Competitividade do Brasil no mercado internacional de madeira serrada. Cerne, Lavras, v.18, n.1, p.99-104, 2012.

FLÓREZ, J.B. Caracterização tecnológica da madeira jovem de teca (Tectona grandis). 2012., 85p. Dissertação (Mestrado em Ciência e Tecnologia da Madeira) Universidade Federal de Lavras, Lavras, 2012. 


\section{(0) \\ Revista Agrarian \\ ISSN: 1984-2538}

GOMES, F.P e GARCIA, C.F. Estatística aplicada a experimentos agronômicos e Florestais. $11^{\circ}$ ed. Piracicaba: Fealq, 2002. 309p.

MATOS, F.S.; TORRES JUNIOR, H.D.; ROSA, V.R.; SANTOS, P.G.F.; BORGES, L.F.O.; RIBEIRO, R.P.; NEVES, T.G.; CRUVINEL, C.K.L. Estratégia morfofisiológica de tolerância ao déficit hídrico de mudas de pinhão manso. Magistra, Cruz das Almas, v.26, n.1, p.19-27, 2014.

$\mathrm{R}$ CORE TEAM, R: A language and environment for statistical computing, $\mathrm{R}$ Foundation for Statistical Computing, Vienna, Austria, Disponível em: <http://www,Rproject,org/>, Acesso em: 30/03/2017.

SÁ, C.P.; FIGUEIREDO, E.O.; OLIVEIRA, L.C. Caracterização e Análise da Rentabilidade Financeira do Cultivo da Teca (Tectona grandis L.f.) para Produção de Madeira em Rio Branco, Acre. Circular Técnica Embrapa. Rio Branco-AC; Junho, 2010.

SAMBATTI, J., CAYLOR, K.K. When is breeding for drought tolerance optimal if drought is random?. New Phytologist, Cambridge, v.175, n.1, p.70-80, 2007.

SANTANA, M.J.; CARVALHO, J.A.; SILVA, E.L. \& MIGUEL, D.S. Efeito da irrigação com água salina em um solo cultivado com o feijoeiro (Phaseolus vulgaris L.). Ciência e Agrotecnologia, Lavras, v.27, p.443-450, 2011.

SCHUHLI, G.S.; PALUDZYSZYN FILHO, E. O cenário nacional da silvicultura de teca e perspectivas para o melhoramento genético. Pesquisa Florestal Brasileira. v.30, n.63, 2010.

SHARP, R.E.; POROYKO, V.; HEJLEK, L.G.; SPOLLEN, W.G.; SPRINGER, G.K.; BOHNERT, H.J.; NGUYEN, H.T. Root growth maintenance during water deficits: physiology to functional genomics. Journal of Experimental Botany, Missouri, v.55, n.407, p.2343-2351, 2004.
SMITH, M. Report on the expert consultation on revision of FAO methodologies for crop water requiremebts. Rome FAO. 45p. 1991.

SOUZA, B.R.; FREITAS, I.A.S.; LOPES, V.A.; ROSA, V.R.; MATOS, F.S. Growth of Eucalyptus plants irrigated with saline water. African Journal of Agricultural Research, Nigéria, v.10, p.1091-1096, 2015.

TAIZ, L.; ZEIGER, E. Fisiologia vegetal. 5.ed. Porto Alegre: Artmed, 2013. 918p.

TONINI, H.; COSTA, M.C.G.; SCWENGBER, L.A.M. Crescimento da Teca (Tectona grandis) em Reflorestamento na Amazônia Setentrional, Pesquisa Florestal Brasileira. v.59, p.5-14, 2009.

WELLBURN, A.R. The spectral determination of chlorophylls a and $b$, as well as total carotenoids, using various solvents with spectrophotometers of different resolution. Journal of Plant Physiology, Jena, v.144, n.3, p.307-313, 1994. 